\title{
Regio-, Diastereo-, and Enantioselective Organocatalytic Addition of 4-Substituted-Pyrazolones to Isatin-Derived Nitroalkenes
} \begin{abstract}
Carmen Muñoz ${ }^{[\mathrm{b}]}$ and José R. Pedro*[a]
Abstract: Hydroquinine 2,5-diphenyl-4,6-pyrimidinediyl diether $\left((\mathrm{DHQ})_{2} \mathrm{Pyr}\right)$ catalyzed the regio-, diastereo- and enantioselective addition of 4-substituted pyrazolones to isatin-derived nitroalkenes, providing a variety of chiral alkenyl-pyrazolone adducts containing a tetrasubstituted stereocenter bearing an oxindole moiety with excellent yields, regioselectivity and diastereoselectivity and moderate enantioselectivity (up to $98 \%$ yield, $>20: 1 \mathrm{E}: Z$ ratio $\mathrm{dr}$ and $78 \%$ ee). The reaction harness a nitroalkene as an alkenylating agent through a Nucleophilic Vinylic Substitution $\left(\mathrm{S}_{\mathrm{N}} \mathrm{V}\right)$ reaction.
\end{abstract}

Carlos Vila, ${ }^{*[a]}$ Nisshanth Raj Dharmaraj, ${ }^{[a]}$ Antonio Faubel, ${ }^{[a]}$ Gonzalo Blay, ${ }^{[a]}$ M. Luz Cardona, ${ }^{[a] ~ M . ~}$

\section{Introduction}

Pyrazolones are an important class of nitrogen heterocycles that have shown a broad range of biological activities and have attracted the attention of the pharmaceutical industry and medicinal chemistry. ${ }^{[1]}$ This scaffold is present in a large variety of synthetic compounds that exhibit pharmaceuticals properties, such as antipyretic, analgesic, neuroprotective, antibacterial, etc. ${ }^{[2]}$ In view of the great importance of the pyrazolone skeleton, the asymmetric synthesis of pyrazolones bearing a quaternary stereocenter have become an attractive goal and many and efficient synthetic approaches have been established over the last years. ${ }^{[3]}$ So, several asymmetric additions of 4-substitutedpyrazol-3-ones to different electrophiles have been reported employing organo- and metal-catalysts for the synthesis of chiral pyrazolones bearing a tetrasubstituted stereocenter at 4 position, particulary when the substituent at this position is an alkyl group. ${ }^{[4]}$ Nevertheless, the examples in the literature of enantioselective synthesis of chiral 4-alkenyl-4-substituted-pyrazolones are scarce. ${ }^{[5,6]}$ Feng an coworkers, ${ }^{[5]}$ in 2012, described a Z-selective asymmetric 1,4 -addition reaction of 4 -substituted pyrazolones to alkynones catalyzed by an $N, N$-dioxide-scandium(III) complex obtaining 4-alkenyl-4-substituted-pyrazolones with high geometric control, high yields, and excellent enantioselectivities (Figure 1). In view of the limited examples described, the development of other methodologies for the synthesis of chiral 4alkenyl-4-substituted-pyrazolones is the great interest for organic synthesis.

[a] Dr. C. Vila, N. Raj Dharmaraj, A. Faubel, Prof. Dr. G. Blay, Prof. Dr. L. Cardona, Prof. Dr. J. R. Pedro

Departament de Química Orgànica, Facultat de Química, Universitat de València, Dr. Moliner 50, 46100 Burjassot, València (Spain)

E-mail: carlos.vila@uv.es; jose.r.pedro@uv.es

[b] Prof. Dr. M. C. Muñoz

Departament de Física Aplicada, Universitat Politècnica de

València, Camino de Vera s/n, 46022 València (Spain)

Supporting information for this article is given via a link at the end of the document.((Please delete this text if not appropriate))

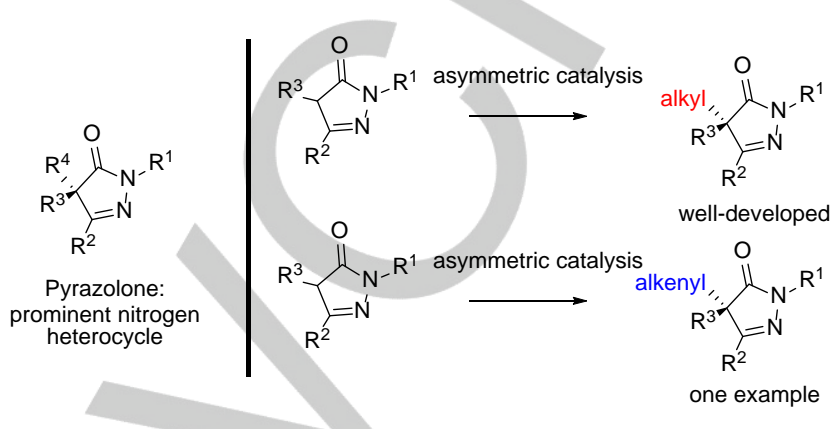

Figure 1. Enantioselective synthesis of chiral pyrazolones bearing a quaternary

On the other hand, 2-oxindole scaffold represents one of the most important structures for medicinal and pharmaceutical chemistry, due to the plenty of natural products and synthetic compounds bearing this motif that present biological activities. ${ }^{[7]}$ As an important 2-oxindole structure, unsymmetrical 3alkylideneoxindoles ${ }^{[8]}$ are present in various natural products ${ }^{[9]}$ and pharmaceutical drugs. ${ }^{[10]}$ We envisioned that the synthesis of chiral pyrazolones bearing a 3-alkylideneoxindoles could be achieved by nucleophilic vinylic substitution $\left(S_{N} V\right)^{[11]}$ of $4-$ substituted-pyrazolones and (E)-3-(nitromethylene)indolin-2one $^{[12]}$ (Scheme 1). However, the nucleophilic vinylic substitution in isatin-derived nitroalkenes have been scarcely studied. ${ }^{[13]}$ Such transformation presents three challenges: the regioselectivity of the nucleophilic addition (attack at the $\beta$-position of the nitroalkene or at the $\alpha$-position), the stereoselectivity of the 1,2elimination and the enantioselectivity of the reaction. We have recently described a stereoselective addition of pyrazolones to isatin-derived nitroolefins in a racemic form. ${ }^{[14]}$ As a part of our ongoing interest in the asymmetric addition of pyrazolones, ${ }^{[15]}$ herein, we wish to report the addition of 4-substituted pyrazolones to isatin-derived nitroalkenes using a (DHQ) $)_{2} \mathrm{Pyr}$ as an organocatalyst through a nucleophilic vinylic substitution $\left(S_{N} V\right)$, leading to chiral heterocyclic compounds containing both 3alkylidene-2-oxindole and pyrazolone moieties bearing a fully carbon tetrasubstituted stereocenter with good yields, excellent regio- and diastereoselectivity and moderate enantioselectivity (Scheme 1). stereocenter at 4-position. 
Enantioselective Nucleophilic Vinylic Substitution $\left(\mathrm{S}_{\mathrm{N}} \mathrm{V}\right) \mathrm{O}$

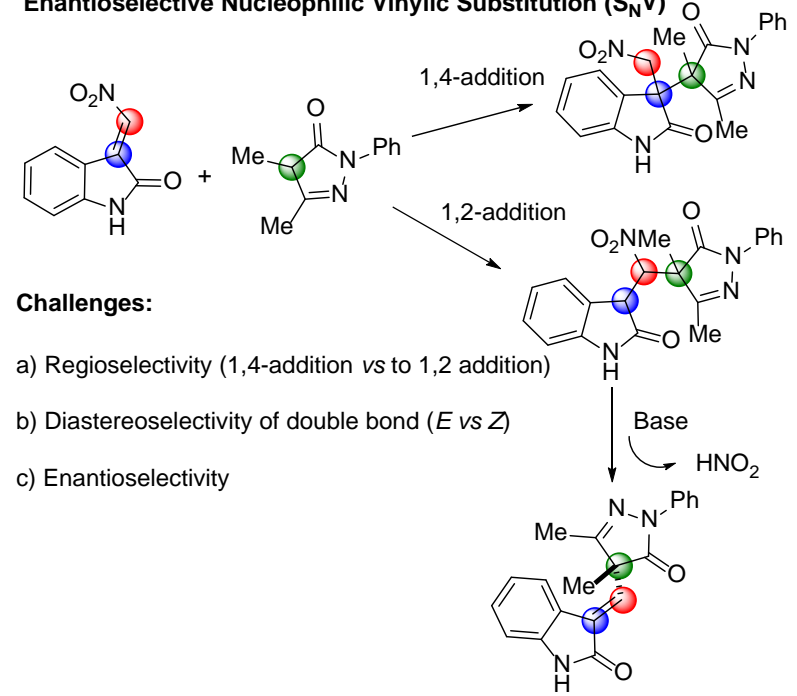

Scheme 1. Asymmetric synthesis of chiral pyrazolones bearing a 3-alkylidene2-oxindole scaffold.

\section{Results and Discussion}

We initiated our studies by evaluating the nucleophilic addition of 4,5-dimethyl-2-phenyl-2,4-dihydro-3H-pyrazol-3-one $2 \mathrm{a}$ to $(E)-1$ benzyl-3-(nitromethylene)indolin-2-one (1a) with various bifunctional organocatalysts $(5 \mathrm{~mol} \%)$ in toluene at room temperature (Table 1). To our delight, quinine A could catalyze the reaction and the product 3aa was obtained with $72 \%$ yield, after 4 hours, with a poor 2:1 E:Z ratio, but with a promising $70 \%$ ee (entry 1, Table 1). When cinchonidine $\mathbf{B}$ was used as catalyst similar results were obtained although with lower enantioselectivity $(47 \%$ ee, entry 2$)$. While product 3aa was obtained with lower $E: Z$ ratio with hydroquinine $\mathbf{C}$ (entry 3 ) and with lower enantiomeric excess (59\% ee, entry 4) with quinidine D. Cupreine derivative $\mathbf{E}$ showed higher $E: Z$ ratio(4:1), but the product 3aa was obtained with lower enantioselectivity ( $41 \%$ ee). When quinine-derived thiourea $\mathbf{F}$ was used, the reaction proceed with lower enantioselectivity, however the Takemoto's thiourea G (entry 7) afforded product 3aa with a good diastereomeric ratio of $7: 1$ and $52 \%$ ee. Next different chiral squaramides were evaluated as catalysts (entries 8 and 9), showing that when quinine-derived squaramide $\mathbf{H}$ was used, the oxindole 3aa was obtained with excellent $E: Z$ ratio (14:1) and $50 \%$ ee. Catalyst (DHQ) ${ }_{2}$ PHAL J (entry 10$)$ and $(\mathrm{DHQ})_{2}$ Pyr $\mathbf{K}$ (entry 11 ), were also tested in the $S_{N} V$ reaction, obtaining similar $E: Z$ ratio than catalyst $\mathbf{H}$, but slighlty better enantioselectivities (53 and $54 \%$ ee, respectively). Finally, the ammonium salt $\mathbf{L}$, gave practically pure the $E$ isomer but with very low enantioselectivity (entry 12). Although quinine A gave better enantioselectivity $(70 \% \text { ee) than (DHQ) })_{2} \mathrm{Pyr}$ K $(54 \%$ ee), catalyst $K$ gave the best $E: Z$ ratio (16:1), while the diastereomeric ratio in the case of the quinine was very poor (2:1). In view of these results, we decided to choose catalyst $\mathbf{K}$ to continue further optimization by testing different solvents (Table 2). ${ }^{[16]}$
Table 1. Optimization of the catalyst.



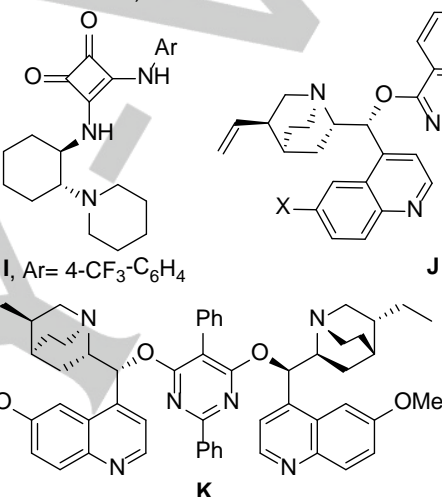

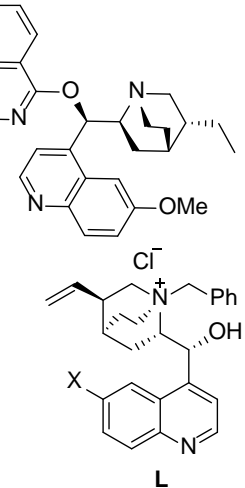

\begin{tabular}{|c|c|c|c|c|c|}
\hline Entry $^{[a]}$ & $\begin{array}{l}\text { Catalyst (5 } \\
\mathrm{mol} \%)\end{array}$ & $t(h)$ & $\begin{array}{l}\text { Yield } \\
(\%)^{[b]}\end{array}$ & $\begin{array}{l}E: Z \\
\text { ratio }{ }^{[c]}\end{array}$ & $\begin{array}{l}\text { Ee of the } E \\
\text { isomer }(\%){ }^{[d]}\end{array}$ \\
\hline 1 & A & 4 & 72 & $2: 1$ & 70 \\
\hline 2 & B & 5 & 70 & $2.2: 1$ & 47 \\
\hline 3 & C & 6 & 69 & 1.1:1 & 69 \\
\hline 4 & D & 4 & 73 & 2.3:1 & $59^{[e]}$ \\
\hline 5 & $E$ & 5 & 62 & $4: 1$ & $41^{[\mathrm{e}]}$ \\
\hline 6 & $F$ & 5 & 55 & $3: 1$ & 31 \\
\hline 7 & G & 3 & 53 & $7: 1$ & $52^{[\mathrm{e}]}$ \\
\hline 8 & $\mathbf{H}$ & 5 & 71 & $14: 1$ & 50 \\
\hline 9 & I & 5 & 54 & $4: 1$ & $33^{[e]}$ \\
\hline 10 & $\mathbf{J}$ & 7 & 50 & $12: 1$ & 53 \\
\hline 11 & $\mathrm{~K}$ & 5 & 72 & $16: 1$ & 54 \\
\hline 12 & $\mathbf{L}$ & 8 & 78 & $>20: 1$ & 10 \\
\hline
\end{tabular}

[a] Reaction conditions: $0.05 \mathrm{mmol} \mathbf{1 a}, 0.1 \mathrm{mmol} \mathbf{2 a}$ and catalyst $(5 \mathrm{~mol} \%)$ in toluene $(1 \mathrm{~mL})$ at $\mathrm{rt}$. [b] Isolated yield after column chromatography. [c] $E: Z$ ratio determined by ${ }^{1} \mathrm{H}$ NMR of the crude reaction mixture. [d] Enantiomeric excess determined by chiral HPLC. [e] Opposite enantiomer. 
Therefore, a wide survey of solvents was tested for the $\mathrm{S}_{\mathrm{N}} \mathrm{V}$ reaction between $\mathbf{1 a}$ and $\mathbf{2 a}$ using $5 \mathrm{~mol} \%$ of catalyst $\mathbf{K}$. First, different aromatic solvents such toluene, benzene, $o$-xylene, $p$ $x y l e n e$, and (trifluoromethyl)benzene were evaluated obtaining product 3aa with high $E: Z$ ratio and good enantiomeric excess, being the best solvent benzene (80\% yield, $16: 1 \mathrm{E:Z}$ ratio, $66 \%$ ee, entry 2). Chlorinated solvents such $\mathrm{CH}_{2} \mathrm{Cl}_{2}$ and $\mathrm{CHCl}_{3}$ were less efficient (entries 6 and 7, respectively). Also ethereal solvents such $\mathrm{Et}_{2} \mathrm{O}$, THF and dioxane gave bad results in terms of enantioselectivity. However, when MTBE was used as a solvent (entry 11 , Table 2) an excellent $98 \%$ yield, excellent $>20: 1 E: Z$ ratio and $64 \%$ ee was obtained. Other polar solvents such EtOAc or $\mathrm{CH}_{3} \mathrm{CN}$ and protic solvents such as $\mathrm{iPrOH}$, gave poor results. In view of these results, we decided to choose benzene and MTBE as solvents to further study of the optimization of the reaction conditions.

Table 2. Optimization of the solvent in the $S_{N} V$ reaction

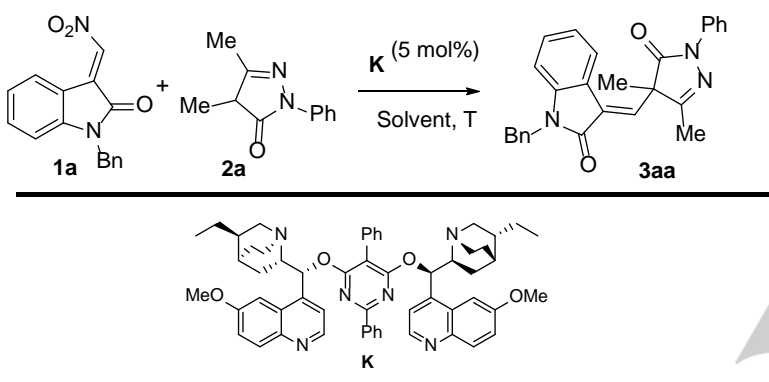

\begin{tabular}{|c|c|c|c|c|c|}
\hline Entry ${ }^{[a]}$ & Solvent & $t(h)$ & Yield $(\%)^{[b]}$ & $E: Z$ ratio ${ }^{[c]}$ & $\begin{array}{l}\text { Ee of the } E \\
\text { isomer }(\%){ }^{[d]}\end{array}$ \\
\hline 1 & toluene & 5 & 72 & $16: 1$ & 54 \\
\hline 2 & benzene & 7 & 80 & $16: 1$ & 66 \\
\hline 3 & $p$-xylene & 5 & 63 & $12: 1$ & 59 \\
\hline 4 & o-xylene & 5 & 69 & $15: 1$ & 58 \\
\hline 5 & $\mathrm{PhCF}_{3}$ & 2 & 65 & $15: 1$ & 56 \\
\hline 6 & $\mathrm{CH}_{2} \mathrm{Cl}_{2}$ & 24 & 62 & $9: 1$ & 28 \\
\hline 7 & $\mathrm{CHCl}_{3}$ & 24 & 65 & $10: 1$ & 40 \\
\hline 8 & $\mathrm{Et}_{2} \mathrm{O}$ & 2 & 78 & $8: 1$ & 25 \\
\hline 9 & THF & 1 & 86 & $8: 1$ & 23 \\
\hline 10 & dioxane & 1 & 97 & $20: 1$ & 33 \\
\hline 11 & MTBE & 5 & 98 & $>20: 1$ & 64 \\
\hline 12 & EtOAc & 5 & 92 & $15: 1$ & 56 \\
\hline 13 & $\mathrm{CH}_{3} \mathrm{CN}$ & 5 & 62 & $13: 1$ & 2 \\
\hline 14 & $i-\mathrm{PrOH}$ & 24 & 77 & $8: 1$ & 15 \\
\hline
\end{tabular}

[a] Reaction conditions: $0.05 \mathrm{mmol} \mathbf{1 a}, 0.1 \mathrm{mmol} \mathbf{2 a}$ and catalyst $(5 \mathrm{~mol} \%)$ in solvent $(1 \mathrm{~mL})$ at $\mathrm{rt}$. [b] Isolated yield after column chromatography. [c] $E: Z$ ratio determined by ${ }^{1} \mathrm{H}$ NMR of the crude reaction mixture. [d] Enantiomeric excess determined by chiral HPLC.
Next, we evaluated the catalyst loading used in the asymmetric $S_{N} V$ reaction (Table 3 ). When a catalyst loading of 10 mol\% was used, lower enantioselectivity was obtained (entry 2 ), while when 2 mol\% of catalyst was used lower yield of compound 3aa was achieved, observing similar enantioselectivity (entries 3). We also observed a decrease in the enantioselectivity of the reaction when MTBE was used as solvent (entries 5 and 6). Moreover, the concentration of the reaction mixture was evaluated (entries 7 and 8), observing lower enantioselectivities. At this point, we decided to study mixtures of benzene:MTBE as solvent to perform the reaction (entries 9 and 10). When $1 \mathrm{~mL}$ of a mixture benzene:MTBE $(0.7: 0.3)$ was used, the corresponding product 3aa was obtained with $97 \%$ yield, excellent $>20: 1 \quad E: Z$ ratio and the best enantioselectivity ( $68 \%$ ee). Finally, by lowering the reaction temperature to $4{ }^{\circ} \mathrm{C}$ (entry 11), the enantioselectivity decreased to $64 \%$ ee.

Table 3. Optimization of the reaction conditions.



\begin{tabular}{|c|c|c|c|c|c|}
\hline Entry ${ }^{[a]}$ & Solvent & $t(h)$ & $\begin{array}{l}\text { Yield } \\
(\%)^{[b]}\end{array}$ & $\begin{array}{l}E: Z \\
\text { ratio }{ }^{[c]}\end{array}$ & $\begin{array}{l}\text { Ee of the } E \\
\text { isomer }(\%)^{[d]}\end{array}$ \\
\hline 1 & benzene & 7 & 80 & $16: 1$ & 66 \\
\hline $2^{[\mathrm{e}]}$ & benzene & 2 & 88 & $16: 1$ & 57 \\
\hline $3^{[f]}$ & benzene & 6 & 67 & $16: 1$ & 65 \\
\hline 4 & MTBE & 5 & 98 & $>20: 1$ & 64 \\
\hline $5^{[e]}$ & MTBE & 1 & 90 & $>20: 1$ & 48 \\
\hline $6^{[f]}$ & MTBE & 7 & 78 & $20: 1$ & 50 \\
\hline $7^{[\mathrm{g}]}$ & benzene & 2 & 81 & $15: 1$ & 58 \\
\hline $8^{[\mathrm{h}]}$ & benzene & 7 & 90 & $17: 1$ & 55 \\
\hline 9 & $\begin{array}{l}\text { benzene:MTBE } \\
(1: 1)\end{array}$ & 1 & 88 & $>20: 1$ & 64 \\
\hline 10 & $\begin{array}{l}\text { benzene:MTBE } \\
(0.7: 0.3)\end{array}$ & 1 & 97 & $>20: 1$ & 68 \\
\hline $11^{[i]}$ & $\begin{array}{l}\text { benzene:MTBE } \\
(0.7: 0.3)\end{array}$ & 7 & 63 & $>20: 1$ & 64 \\
\hline
\end{tabular}

[a] Reaction conditions: $0.05 \mathrm{mmol} \mathbf{1 a}, 0.1 \mathrm{mmol} \mathbf{2 a}$ and catalyst $(5 \mathrm{~mol} \%)$ in solvent $(1 \mathrm{~mL})$ at $\mathrm{rt}$. [b] Isolated yield after column chromatography. [c] $E: Z$ ratio determined by ${ }^{1} \mathrm{H}$ NMR of the crude reaction mixture. [d] Enantiomeric excess determined by chiral HPLC. [e] 10 mol\% of catalyst $\mathbf{K}$ was used. [f] $2.5 \mathrm{~mol} \%$ of catalyst $\mathbf{K}$ was used. [g] $2 \mathrm{~mL}$ of benzene was used. [h] $0.5 \mathrm{~mL}$ of benzene was used. [i] The reaction was performed at $4{ }^{\circ} \mathrm{C}$. 
With the optimized reaction conditions in hand (entry 10 Table 3), we proceeded to study the scope of the enantioselective addition of pyrazolones $\mathbf{2}$ to isatin-derived nitroalkenes $\mathbf{1}$ through a $S_{N} V$ reaction (Scheme 2). Electron-donating (MeO, Me) or electron-withdrawing $(\mathrm{Cl})$, were tolerated at the 5,6 or 7 position of the isatin-derived nitroalkene, affording the corresponding products (3ba-3da) with good yields, excellent $E: Z$ ratios and good enantiomeric excesses (up to $78 \%$ ee). Next, the $\mathrm{N}$ substitution of the oxindole nitrogen was evaluated (3ea-3ia). Groups such as methyl, allyl and propargyl were well accommodated, obtaining the corresponding 3-alkylidene-2oxindoles $\mathbf{3}$ with better enantioselectivities (up to $78 \%$ ee). Nonprotected $\mathrm{NH}$ on the oxindole ring was also tolerated (3ha), although with lower yield, diastereoselectivity (10:1 E:Z ratio) and enantioselectivity (54\% ee). Different pyrazolones 2 were also evaluated in the reaction with nitroalkenes 1 . The reaction proceeded efficiently with high yields and excellent diastereoselectivity, although with lower enantioselectivity (53$69 \%$ ee).

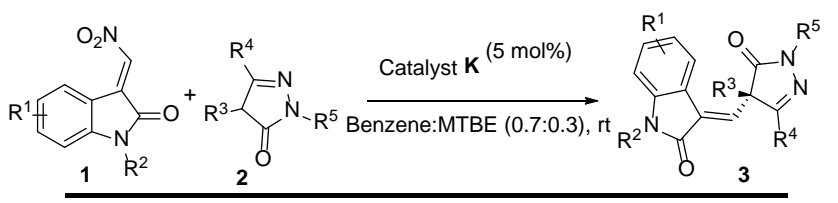

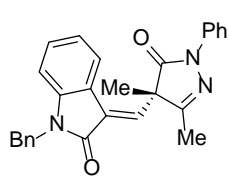

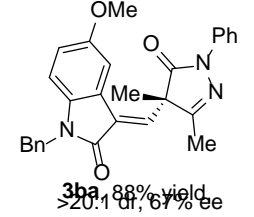

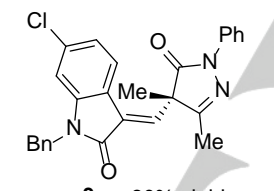
$3 \mathrm{ca}_{1} 8 \mathrm{Af} \%$ \%iglde<smiles>Cc1cc(C)c2c(c1)C(=CC1C(=O)C(Nc3ccccc3)=NC1C)C(=O)N2Cc1ccccc1</smiles><smiles>C=CC=CC1=NN(c2ccccc2)C(=O)C1(C)C=C1C(=O)N(C)c2ccccc21</smiles>
20:1 3 (20:1) dr, 74\% (72\%) ee

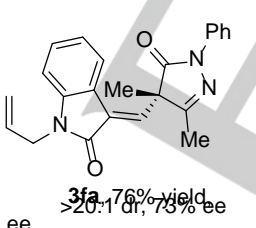
(97\% ee after crist,)




OMe<smiles>COc1ccc2c(c1)C(=O)N(Cc1ccccc1)C(=O)C2=CC(=O)C(C)C(=O)Nc1ccccc1</smiles>

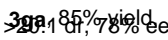

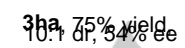$$
\text { 3bb, 95\% yield, }
$$

$20: 1 \mathrm{dr}, 69 \%$ ee $\mathrm{NO}_{2}$

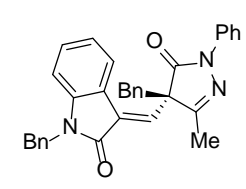

3ac, $81 \%$ yield $20: 1 \mathrm{dr}, 60 \%$ ee

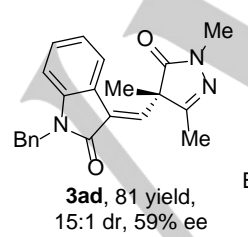
$15: 1 \mathrm{dr}, 59 \%$ ee

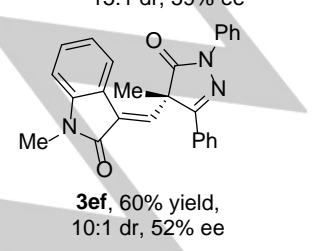

Scheme 2. Scope of the enantioselective addition of 4-substituted-pyrazolones to isatin-derived nitroalkenes. Reaction conditions: $0.05 \mathrm{mmol} \mathbf{1}, 0.1 \mathrm{mmol} 2$ and catalyst $\mathbf{K}(5 \mathrm{~mol} \%)$ in benzene $(0.7 \mathrm{~mL})$ :MTBE $(0.3 \mathrm{~mL})$. Isolated yield after column chromatography. E:Z ratio determined by ${ }^{1} \mathrm{H}$ NMR of the crude mixture. Enantiomeric excess determined by chiral HPLC. ${ }^{a}$ The results in parenthesis corresponds to the $1 \mathrm{mmol}$ scale reaction.

The configuration of the double bond in compound 3fa was determined as $E$ and the absolute configuration of the stereogenic center was determined to be $(S)$ on the basis of X-ray crystallographic analysis (Figure 2); the configuration of the rest of the products $\mathbf{3}$ were assigned on the assumption of a uniform mechanistic pathway. ${ }^{[17]}$
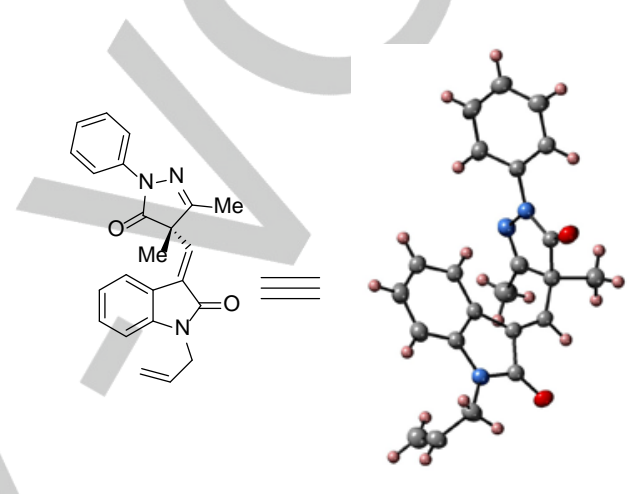

Figure 2. X-ray crystal structure of $\mathbf{3 f a}$.

On the basis of the absolute configuration of $\mathbf{3 f a}$, we propose a plausible mechanism for the stereoselective $S_{N} V$ reaction as is shown in the Scheme 3. By the action of one quinuclidine moieties of $(\mathrm{DHQ})_{2} \mathrm{Pyr}$, the pyrazol-3-one $\mathbf{2}$ is activated by hydrogen bonding, for the regioselective nucleophilic addition of the pyrazol-3-one to the a-position of nitroalkene 1, that could be coordinated to the catalyst by $\pi-\pi$ stacking interactions. After the nucleophilic addition of $\mathbf{2}$, the intermediate switches to an eclipsed conformation, which is favored by an intramolecular hydrogen bond between the nitro group and the hydrogen of the $\mathrm{C}-3$ of oxindole through a five-membered ring. ${ }^{[13,14]}$ In this case, in the presence of a base (the quinuclidine moiety of the (DHQ) $)_{2} \mathrm{Pyr}$ catalyst), the hydrogen bond prompts a fast 1,2-cis-elimination to afford the E-3-alkenyl-2-oxindole $\mathbf{3 f a}$ as the major product.






\section{Conclusions}

We have developed a catalytic enantioselective addition of 4substituted-pyrazolones to isatin-derived nitroalkenes catalyzed by (DHQ) ${ }_{2}$ Pyr, obtaining chiral pyrazolones bearing a quaternary stereocenter at 4 position with a 3-alkylidene-2-oxindole moiety with excellent yields (up to $97 \%$ ), excellent $E: Z$ ratio (up to $>20: 1$ ) and moderate enantioselectivities (up to $78 \%$ ee). The reaction consists in a regioselective nucleophilic vinylic substitution $\left(S_{N} V\right)$, where the nitro group acts as leaving group for delivering 3alkylidene-2-oxindoles. The enantioselectivities are moderate, however taking into account that we obtain one of the several possible isomers, the present methodology represents an interesting synthetic way to obtain chiral 3-alkylidene-2-oxindoles. An advantage of our system is that the organocatalyst is commercially available and the reaction conditions are mild.

\section{Acknowledgements}

Financial support from the Agencia Estatal de Investigación (AEI, Spanish Government) and Fondo Europeo de Desarrollo Regional (FEDER, European Union) (CTQ2017-84900-P) is acknowledged. C.V. thanks the Spanish Government for Ramón y Cajal contract (RYC-2016-20187). Access to NMR, MS and Xray facilities from the Servei Central de Suport a la Investigació Experimental (SCSIE)-UV is also acknowledged.

Keywords: asymmetric catalysis • isatin-derived nitroalkenes• pyrazolones • organocatalysis • Nucleophilic Vinylic Substitution

[1] G. Varvounis, in Pyrazol-3-ones. Part IV: Synthesis and Applications, ed. A. R. Katritzky, Advances in Heterocyclic Chemistry, Academic Press, New York, 2009, vol. 98, p. 143.

[2] a) "Dipyrone". Martindale: The Complete Drug Reference, ed. A. Brayfield, Pharmaceutical Press, 2014; b) Y. Fujimori, K. Katsuno, I. Nakashima, Y. Ishikawa-Takemura, H. Fujikura, M Isaji, J. Pharmacol. Exp. Ther. 2008, 327, 268-276; c) H. Yoshida, H. Yanai, Y. Namiki, K. Fukatsu-Sasaki, N. Furutani, N. Tada, CNS Drug Rev., 2006, 12, 9-20; d) N. Yokoyama, B. Ritter, A. D. Neubert, J. Med. Chem. 1982, 25, 337 339; e) R. I. Fryer, P. Zhang, R. Rios, Z.-Q. Gu, A. S. Basile, P. Skolnick, J. Med. Chem. 1993, 36, 1669-1673; f) L. Savini, P. Massarelli, C Nencini, C. Pellerano, G. Biggio, A. Maciocco, G. Tuligi, A. Carrieri, N. Cinone, A. Carotti, Bioorg. Med. Chem. 1998, 6, 389-399; g) F. Caruso M. Rossi, J. Tanski, R. Sartori, R. Sariego, S. Moya, S. Diez, E. Navarrete, A. Cingolani, F. Marchetti, C. Pettinari, J. Med. Chem. 2000, 43, 36653670; h) M. G. Ferlin, G. Chiarelotto, S. D. Acqua, E. Maciocco, M. P. Mascia, M. G. Pisu, G. Biggio, Bioorg. Med. Chem. 2005, 13, 3531-3541.

[3] a) P. Chauhan, S. Mahajan, D. Enders, Chem. Commun, 2015, 51, 12890-12907; b) S. Liu, X. Bao, B. Wang, Chem. Commun, 2018, 54, 11515-11529.

[4] For selected examples, see: a) Y.-H. Liao, W.-B. Chen, Z.-J. Wu, X.-L. Du, L.-F. Cun, X.-M. Zhang, W.-C. Yuan, Adv. Synth. Catal. 2010, 352, 827-832; b) Z. Wang, Z. Yang, D. Chen, X. Liu, L. Lin, X. Feng, Angew. Chem. Int. Ed. 2011, 50, 4928-4932; c) A. Mazzanti, T. Calbet, M. FontBardia, A. Moyano, R. Rios, Org. Biomol. Chem. 2012, 10, 1645-1652; d) Z.-L. Tao, W.-Q. Zhang, D.-F. Chen, A. Adele, L.-Z. Gong, J. Am. Chem. Soc. 2013, 135, 9255-9258; e) H. Zhou, Z. Wei, J. Zhang, H. Yang, C. Xia, G. Jiang, Angew. Chem. Int. Ed. 2017, 56, 1077-1081; f) K. Yang, X. Bao, S. Liu, J. Xu, J. Qu, B. Wang, Eur. J. Org. Chem. 2018, DOI: 10.1002/ejoc.201801039.

[5] Z. Wang, Z. Chen, S. Bai, W. Lei, X. Liu, L. Lin, X. Feng, Angew. Chem. Int. Ed. 2012, 51, 2776-2779.

[6] For the synthesis of chiral 4-aryl-4-substituted-pyrazolones, see: Z.-Q. Zhu, Y. Shen, J.-X. Liu, J.-Y. Tao, F. Shi, Org. Lett. 2017, 19, 1542-1545. For the synthesis of racemic 4-alkenyl-4-substituted-pyrazolones, see b) K. Yang, X. Bao, Y. Yao, J. Qu, B. Wang, Org. Biomol. Chem. 2018, 16 6275-6283.

[7] a) C. Marti, E. M. Carreira, Eur. J. Org. Chem. 2003, 2209-2219; b) C. V. Galliford, K. A. Scheidt, Angew. Chem. Int. Ed. 2007, 46, 8748-8758; c) B. M. Trost, M. K. Brennan, Synthesis 2009, 3003-3025; d) J. Klein, R. Taylor, Eur. J. Org. Chem. 2011, 6821-6841. For recent reviews of synthesis of chiral 2-oxindole derivatives, see: e) J.-S. Yu, F. Zhou, Y.-L. Liu, J. Zhou, Synlett 2015, 26, 2491-2504; f) G.-J. Mei, F. Shi, Chem. Commun. 2018, 54, 6607-6621. For some recent examples, see: g) L.-J. Zhou, Y.-C. Zhang, F. Jiang, G. He, J. Yan, H. Lu, S. Zhang, F. Shi, Adv. Synth. Catal. 2016, 358, 3069; h) F. Jiang, D. Zhao, X. Yang, F.-R. Yuan, G.-J. Mei, F. Shi, ACS Catal. 2017, 7, 6984-6989; i) W. Guo, Y. Liu, C. Li, Org. Lett. 2017, 19, 1044.

[8] A. Millemaggi, R. Taylor, Eur. J. Org. Chem. 2010, 4527-4547.

[9] a) K. Hata, K. Baba, M. Kozawa, Chem. Pharm. Bull. 1978, 26, 2279 2280; b) B. Weniger, Y. Jiang, R. Anton, J. Bastida, T. Varea, J.-C Quirion, Phytochemistry 1993, 32, 1587-1590; c) X. Wu, Y. Liu, W Sheng, J. Sun, G. Qin, Planta Med. 1997, 63, 55-57; d) M. S. C. Pedras, P. B. Chumala, M. Suchy, Phytochemistry 2003, 64, 949-956; e) I. Fatima, I. Ahmad, I. Anis, A. Malik, N. Afza, Molecules 2007, 12, 155162; g) L. Zhou, J.-S. Yang, X. Wu, J.-H. Zou, X.-D. Xu, G.-Z. Tu, Heterocycles 2005, 65, 1409-1414.

[10] a) L. Xu, Y. Hao, X. Wu, P. Yu, G. Zhu, Z. Hong, Neurolog. Res. 2013, 35 561-567; b) T. Kimura, M. Uesugi, K. Takase, N. Miyamoto, K. Sawada, Toxicol. Appl. Pharmacol. 2017, 329, 282-292; c) L. Sun, N. Tran, F. Tang, H. App, P. Hirth, G. McMahon, C. Tang, J. Med. Chem. 1998, 41, 2588-2603; d) T. Fong, L. K. Shawver, L. Sun, C. Tang, H. App, T. Powell, Y. Kim, R. Schreck, X. Wang, W. Risau, A. Ullrich, K. Hirth, G. McMahon, Cancer Res. 1999, 59, 99-106; e) M. Mohammadi, G. McMahon, L. Sun, C. Tang, P. Hirth, B. Yeh, S. Hubbard, R. Schlessinger, Science 1997, 276, 955-960.

[11] F. C. Bernasconi, Z. Rappoport, Acc. Chem. Res. 2009, 42, 993-1003.

[12] G. Chen, X.-J. Hao, Q.-Y. Sun, J. Ding, Chem. Pap., 2010, 64, 673-677.

[13] H. Zhang, Y. Liu, R. Chen, J. Xue, Y. Li, Y. Tang, Asian J. Org. Chem. 2013, 2, 307-310.

[14] C. Vila, S. Slack, G. Blay, M. C. Muñoz, J. R. Pedro, Adv. Synth. Catal. 2018, DOI:10.1002/adsc.201900048.

[15] a) C. Vila, F. I. Amr, G. Blay, M. C. Muñoz, J. R. Pedro, Chem. Asian J. 2016, 11, 1532-1536; b) F. I. Amr, C. Vila, G. Blay, M. C. Muñoz, J. R. Pedro, Adv. Synth. Catal., 2016, 358, 1583-1588.

[16] Further optimization with catalyst $\mathbf{A}$ and $\mathbf{J}$ did not improve the results. See supporting information for further details.

[17] CCDC 1899761 (3fa) contains the supplementary crystallographic data for this paper. These data can be obtained free of charge from The Cambridge Crystallographic Data Centre via www.ccdc.cam.ac.uk/data request/cif. 
Entry for the Table of Contents (Please choose one layout)

Layout 2:

\section{COMMUNICATION}

$$
\begin{gathered}
\begin{array}{c}
\text { Good yields (60-97\%) } \\
\text { Excellent diastereoselectivities (10:1 to >20:1 E:Z ratio) } \\
\text { Moderate enantioselectivities (52-78 \% ee) }
\end{array} \\
\text { (DHQ) } 2 \mathrm{Pyr}(5 \mathrm{~mol} \%)
\end{gathered}
$$

Regio-, Diastereo-, and Enantioselective Organocatalytic Addition of 4-SubstitutedPyrazolones to Isatin-Derived Nitroalkenes

Carlos Vila, *[a] Nisshanth Raj Dharmaraj, ${ }^{[a]}$ Antonio Faubel, ${ }^{[a]}$ Gonzalo Blay, ${ }^{[a]}$ M. Luz Cardona, ${ }^{[a]}$ M. Carmen Muñoz ${ }^{[b]}$ and José R. Pedro*[a]

Page No. - Page No.

A regio-, diastereo- and enantioselective organocatalytic enantioselective addition of 4-substituted pyrazolones to isatinderived nitroalkenes has been developed. (DHQ) ${ }_{2}$ Pyr was found to be effective to provide the desired chiral pyrazolones bearing a 3-alkylidene-2-oxindole moiety with excellent yields, excellent $E: Z$ ratio and moderate enantioselectivities. 